\title{
The cardiac cell model at normal and high pacing rates with Markovian representations of gating processes (Computer simulation study)
}

\author{
B. Kogan, J. Better \& I. Zlochistyy \\ Computer Science Department, University of California, Los Angeles, \\ California, USA
}

\begin{abstract}
Over the past years significant results have been achieved in the mathematical modeling and computer simulation of action potential generation and propagation using Hodgkin-Huxley formalism. The development of the single channel clamp experiment technique has provided new experimental data, and also led to a Markovian formulation of the ion channels gating processes. The advantages of this formulation are: it makes the artificial Hodgkin-Huxley assumption of mutual independence of gating processes unnecessary and also opens the possibility of simulating the effects of drugs, toxins and genetic defects in channel proteins on the behavior of cardiac cells.

The comparison of the effect of Markovian and Hodgkin-Huxley representations for major voltage dependent channels presented here shows that at normal pacing rates both representations give the same action potential shape without significant changes in its basic characteristics. For pacing rates encountered during heart tachycardia and fibrillation, we observe that the Markovian representations yield maximum sodium and rapid potassium currents that decrease much more than the corresponding currents in the cell model with the Hodgkin-Huxley formulation. The decrease of the sodium current reduces the depolarization rate and ultimately the velocity of wave propagation. The decrease of the rapid potassium current increases the duration of the action potential and causes early after depolarization in the presence of intracellular calcium accumulation and spontaneous sarcoplasmic reticulum $\mathrm{Ca}^{2+}$ release.
\end{abstract}




\section{Introduction}

Mathematical modeling and computer simulation are becoming increasingly important in studying the mechanisms of cardiac arrhythmias and fibrillation (the principal cause of cardiac sudden death). Computer simulations help to clarify the basic mechanisms of these pathological processes and to develop the appropriate treatments.

Over the past years, significant results have been obtained in the mathematical modeling and computer simulation of action potential (AP) generation and excitation wave propagation in heart tissue using the classical Hodgkin-Huxley $(\mathrm{H}-\mathrm{H})$ formalism 1 . Two generations of AP mathematical models were created using this formalism. The first is based on the Noble model ${ }^{2}$ including its simplifications, and further improvements based on the single cell clamp-experiments data.

The second generation incorporates intracellular $\mathrm{Ca}^{2+}$ dynamics that play a major role in excitation-contraction coupling. $\mathrm{Ca}^{2+}$ dynamics also produce a feedback effect on the shape and duration of the AP affecting $\mathrm{Ca}^{2+}$ dependent currents. For details see the short review ${ }^{3}$. Computer simulations with these models show intracellular $\mathrm{Ca}^{2+}$ accumulation under high pacing rates, which leads to spontaneous $\mathrm{Ca}^{2+}$ release. The latter produces quasiperiodic oscillations of AP and the transition from a stationary spiral wave in a $2 \mathrm{D}$ tissue model to a nonstationary one and followed by wave-front break up. These oscillations occur due to the spatial heterogeneity in intracellular $\mathrm{Ca}^{2+}$ concentration created after some duration of spiral wave propagation ${ }^{4}$.

During the last 15 years, a new approach that is based on the latest achievements of single channel ${ }^{10}$ clamp experiments, has been developed for the mathematical description of the gating processes in voltage dependent channels of cardiac and nerve cell membranes ${ }^{5,6,7,8,9}$. This approach considers channel gating as a Markov process, and opens the possibility of simulating the effects of drugs, toxins and genetic defects in channel proteins on the excitable cell's behavior. More specifically, mathematical models of the cardiac sodium channel have been developed with temperature dependence and recovery from inactivation $^{11}$ and for calcium regulation ${ }^{12}$ in the ventricular myocyte. The effects of genetic defects in both sodium ${ }^{13,14}$ and rapid potassium channels ${ }^{15}$ on cardiac cell behavior have recently been investigated.

However, it remains unclear how the difference in the particular gating process representation used translates into a difference in the cell's behavior at a given pacing rate, even for cells without immune-defects but with normal $\mathrm{Ca}^{2+}$ dynamics. Here we show that the Markovian representations of $\mathrm{Na}$ and $\mathrm{K}_{\mathrm{r}}$ channels give larger decreases of the currents through these channels with pacing rates increased from normal to that corresponding to tachycardia and fibrillation. 


\section{Markovian representation of Sodium channel processes}

\subsection{General considerations}

The effect of Markovian and Hodgkin-Huxley representations of sodium channel gating processes on the major characteristics of the AP is investigated for two cases: when the Basic Cycle Length (BCL) of excitation is normal $(\mathrm{BCL}=1000$ $\mathrm{ms}$ ) and when it has been significantly shortened $(B C L=180 \mathrm{~ms})$. For this purpose we have chosen our modification of the Luo-Rudy ${ }^{16}$ and Zeng ${ }^{17}$ models (in the Hodgkin-Huxley formalism) and replaced in it the value of the open probability $\mathrm{O}_{\mathrm{H}-\mathrm{H}}=\mathrm{m}^{3} \mathrm{hj}$ by $\mathrm{O}_{\mathrm{M}}$ obtained using the Markovian approach.

The cardiac cell sodium macroscopic current is calculated using the equation:

$$
\mathrm{I}_{\mathrm{Na}}=\mathrm{G}_{\mathrm{Na}} * \mathrm{O}^{*}\left(\mathrm{~V}-\mathrm{E}_{\mathrm{Na}}\right)
$$

Here: $\mathrm{V}$ is membrane potential; $\mathrm{E}_{\mathrm{Na}}$ is the Nernst potential for sodium ions; $\mathrm{O}(\mathrm{V}, \mathrm{t})$ is the probability that the sodium channel is in the open state; $\mathrm{G}_{\mathrm{Na}}$ is the maximum conductivity of sodium channels per $\mathrm{cm}^{2}$ of membrane surface.

For the $\mathrm{H}-\mathrm{H}$ representation $\mathrm{O}_{\mathrm{H}-\mathrm{H}}=\mathrm{m}^{3} \mathrm{hj}$. The gate variables $\mathrm{m}, \mathrm{h}$ and $\mathrm{j}$ are solutions of well known first order independent ODEs. For the Markovian representation $\mathrm{O}_{M}$ is obtained as a solution of a system of interconnected ODEs derived from the kinetic model ${ }^{14}$ represented in Fig.1. The full set of equations and the values of the rate constants for the wild-type sodium channel can be found in $^{14}$.

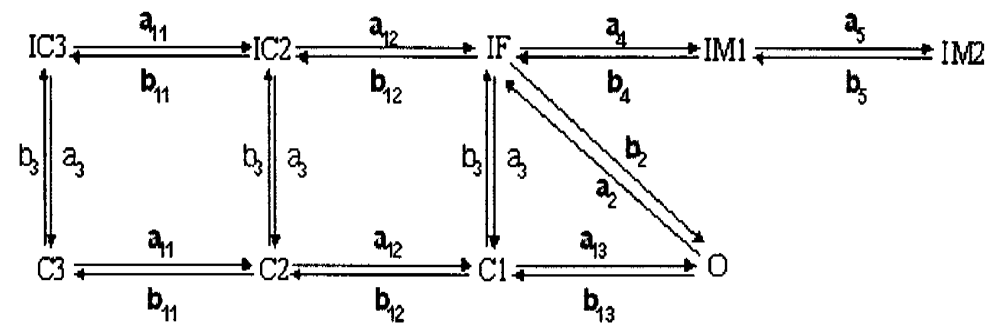

Figure 1: Markovian kinetic models of wild-type Na channel state probabilities

\subsection{Results}

The open probability $O$ of the sodium channel, the sodium current, $I_{\mathrm{Na}}$, and the $\mathrm{AP}$ are shown in Fig. 2 for both representations of channel gating processes at slow (normal) rates of stimulation. 
A
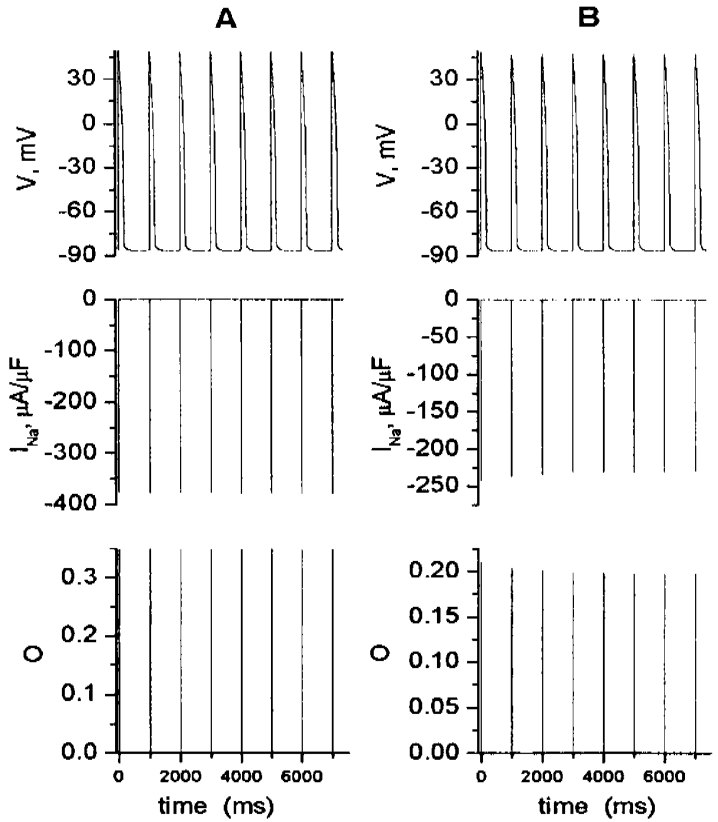

Figure 2: Open probabilities, sodium currents and APs in model ${ }^{4}$ for $\mathrm{BCL}=1000 \mathrm{~ms}$ with different representations of sodium channel gating processes: A: Hodgkin -Huxley $(\mathrm{H}-\mathrm{H}), \mathrm{B}$ : Markovian

The maximum values of the open probabilities and of the corresponding currents, $\mathrm{I}_{\mathrm{Na}}$, vary insignificantly from beat to beat for the cell model with either the $\mathrm{H}-\mathrm{H}$ or the Markovian representation of the gating processes. The absolute values of $\mathrm{O}$ and $\mathrm{I}_{\mathrm{Na}}$ are smaller for the Markovian representation than for the $\mathrm{H}$ $\mathrm{H}$ representation. It is possible to equalize the values of $\mathrm{I}_{\mathrm{Na}}$ for both representations by increasing $G_{\mathrm{Na}}$ for the Markovian representation. Both representations provide the same results at a slow rate of stimulation, as may be seen by comparing the normalized values

$$
\left(\overline{\mathrm{I}}_{\mathrm{Na}}\right)_{\mathrm{Nomm}}=\frac{\left[\left(\overline{\mathrm{I}}_{\mathrm{Na}}\right)_{6}+\left(\overline{\mathrm{I}}_{\mathrm{Na}}\right)_{7}\right] / 2}{\left(\overline{\mathrm{I}}_{\mathrm{Na}}\right)_{1}}
$$

where $\left(\overline{\mathrm{I}}_{\mathrm{Na}}\right)_{\mathrm{i}}, \mathrm{i}=1,6,7$ denotes the maximum sodium currents of the $\mathrm{i}^{\text {th }}$ AP. The simulation data (Fig. 2) show that $\left(\overline{\mathrm{I}}_{\mathrm{Na}}\right)_{\text {Norm }}$ and $\mathrm{O}_{\mathrm{Norm}}$ for both representations differ from each other by $\sim 5 \%$. The results of the same simulation at a high pacing rate are presented in Fig. 3. 
A

B
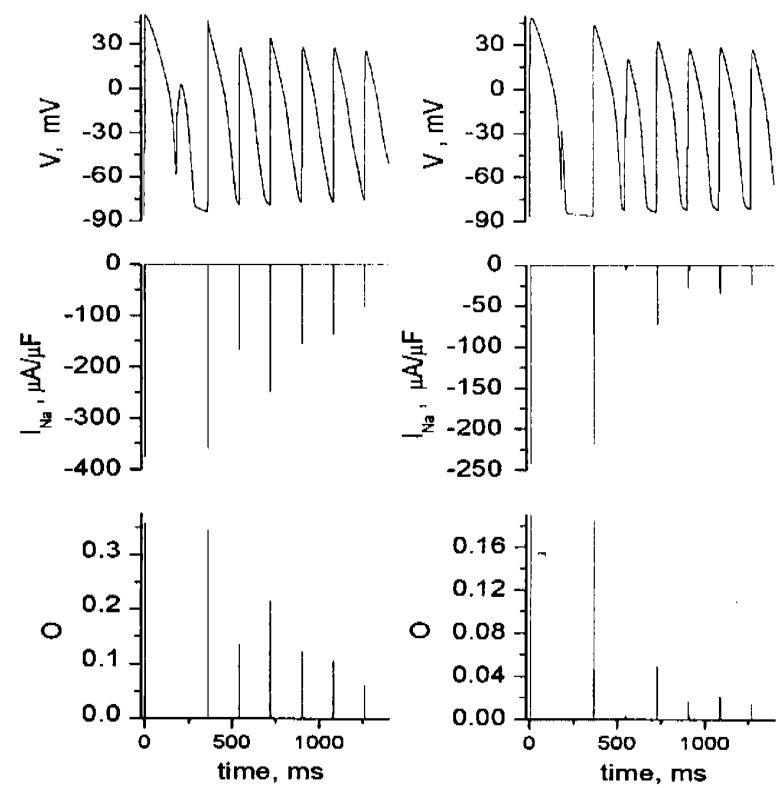

Figure 3: The cell model ${ }^{4}$ at a high pacing rate $(B C L=180 \mathrm{~ms})$ and different representations of sodium channel gating processes: A: $\mathrm{H}-\mathrm{H}$ representation, B: Markovian representation

In choosing representative AP's for $\mathrm{O}_{\max }$ and $\left(\mathrm{I}_{\mathrm{Na}}\right)_{\max }$ at $\mathrm{BCL}=180 \mathrm{~ms}$ we were constrained by the fact that for the rhythm to capture requires a time of close to three periods of stimulation; after $\sim 1200 \mathrm{~ms}$ the accumulation and spontaneous $\mathrm{Ca}^{2+}$ release in our model distort the picture. Therefore, we chose the $6^{\text {th }}$ and $7^{\text {th }}$ APs in $\left(^{*}\right)$. The averages of $(\mathrm{O})_{\max }$ and $\left(\mathrm{I}_{\mathrm{Na}}\right)_{\max }$ for the 6 and $7^{\text {th }}$ APs is taken since there was some variation in the AP characteristics for these two APs.

The simulation data are shown in the Table. 1.

\section{Table I:}

\begin{tabular}{|c|c|c|c|c|c|c|c|c|}
\hline \multirow{3}{*}{ Model } & \multicolumn{6}{|c|}{$\begin{array}{l}\text { Computer simulation data } \\
\mathrm{BCL}=180 \mathrm{~ms}\end{array}$} & \multicolumn{2}{|c|}{$\begin{array}{c}\text { Normalized } \\
\text { data }\end{array}$} \\
\hline & \multicolumn{3}{|c|}{$\begin{array}{c}\mathrm{O}_{\max } \\
\text { for AP.\# }\end{array}$} & \multicolumn{3}{|c|}{$\begin{array}{l}\left(\mathrm{I}_{\mathrm{Na}}\right)_{\max } \\
\text { for AP.\# }\end{array}$} & \multirow{2}{*}{$10^{\frac{1}{2}}$} & \multirow{2}{*}{ 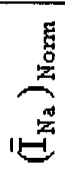 } \\
\hline & 1 & 6 & 7 & 1 & 6 & 7 & & \\
\hline $\mathrm{H}-\mathrm{H}$ & 0.36 & 0.12 & 0.11 & 375 & 150 & 133 & 0.33 & 0.38 \\
\hline Markovian & 0.21 & 0.02 & 0.02 & 241 & 29.2 & 33.3 & 0.08 & 0.13 \\
\hline
\end{tabular}


The normalized values of $\mathrm{O}_{\max }$ and $\left(\mathrm{I}_{\mathrm{Na}}\right)_{\max }=(\mathrm{dv} / \mathrm{dt})_{\max }$ are three times smaller with the Markovian representation than with the $\mathrm{HH}$ formulation.

\section{Markovian model of the gating processes in a rapid Potas- sium channel}

\subsection{General consideration}

Clancy and Rudy's ${ }^{15}$ Markovian kinetic model for wild-type $\mathrm{K}_{\mathrm{r}}$ channel state probabilities is shown in Fig.4. The model includes three closed states $\left(C_{1}, C_{2}\right.$, $\mathrm{C}_{3}$ ), an open state $(\mathrm{O})$, and an inactivation state $(\mathrm{I})$. The transition between $\mathrm{C} 2$ and $\mathrm{C} 1$ is voltage independent.

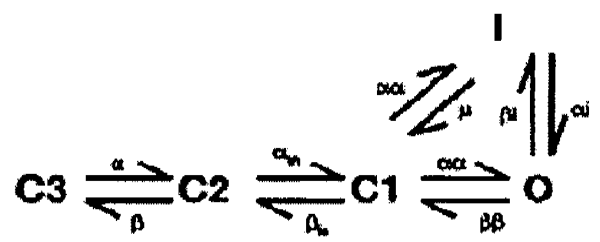

Figure 4: Block diagram for Markovian model of cardiac cell rapid potassium channel.

Closed state inactivation $(\mathrm{Cl} \longrightarrow I)$ is included from a single closed state, allowing for reduced computational time. The transition rate between $\mathrm{Cl}$ and $\mathrm{I}$ is the same as from $\mathrm{C} 1$ to $\mathrm{O}$. $\mathrm{I}_{\mathrm{Kr}}$ exhibits strong inward rectification due to a rapid voltage dependent $\mathrm{C}$-type inactivation at a positive membrane potential (transition from $\mathrm{O}$ to $\mathrm{I}$ ). The transitions between $\mathrm{O}$ and $\mathrm{I}$ are also dependent on extracellurar potassium concentration $\left[\mathrm{K}^{+}\right]_{\text {out }}$. As $\left[\mathrm{K}^{+}\right]_{\mathrm{out}}$ is increased the transition rates decreases.

The Markovian representation of the potassium channel model is described by a system of five linear differential equations, where the variables are the channel's state probabilities and the rate coefficients are either functions of $V_{m}$ or constant. by:

In Clancy and Rudy ${ }^{15}$ the macroscopic rapid potassium current $I_{\mathrm{Kr}}$ is given

$$
\mathrm{I}_{\mathrm{Kr}}=\mathrm{G}_{\mathrm{Kr}} * \mathrm{P}(\mathrm{O}) *\left(\mathrm{~V}_{\mathrm{m}}-\mathrm{E}_{\mathrm{K}}\right)
$$

where: $\mathrm{P}(\mathrm{O})$ - open probability of a channel; $\mathrm{G}_{\mathrm{Kr}}=0.0135 *\left(\left[\mathrm{~K}^{+}\right]_{0}\right)^{0.59}-$ the total maximum value of membrane $\mathrm{K}_{\mathrm{r}}$ channels conductance; $\mathrm{E}_{\mathrm{K}}=(\mathrm{R} * \mathrm{~T} / \mathrm{F}) * \ln \left(\left[\mathrm{K}^{+}\right]_{0} /\left[\mathrm{K}^{+}\right]_{\mathrm{i}}\right)$ - reverse potential; $\mathrm{V}_{\mathrm{m}}-$ membrane potential.

All the channel equations were encoded using $\mathrm{C} / \mathrm{C}++$ and added to the LuoRudy modified cell model ${ }^{4}$. This set of equations was solved using an explicit Euler numerical method with a constant time step of $0.005 \mathrm{~ms}$.

The initial values of the $K_{r}$ channel state probabilities were obtained as the steady state values of these probabilities at the resting potential 
$\left(\mathrm{V}_{\text {rest }}=-86.4 \mathrm{mV}\right)$ in the Markovian model of $\mathrm{K}_{\mathrm{r}}$ channel. The resting potential is a membrane potential at which the net current through the membrane is equal to zero.

\subsection{Results}

The effects of replacing the $\mathrm{H}-\mathrm{H}$ formulation in the cardiac cell model ${ }^{4}$ by a Markovian representation are presented in Fig. 5 for $\mathrm{BCL}=1000 \mathrm{~ms}$. Notice that the Markovian representation gives a smaller maximum value of the channel open probability with more shallow changes during the time of AP. The noticeable decrease in maximum values of $\mathrm{I}_{\mathrm{Kr}}$ has no significant effect on AP shape and duration $(\sim 6 \%)$.
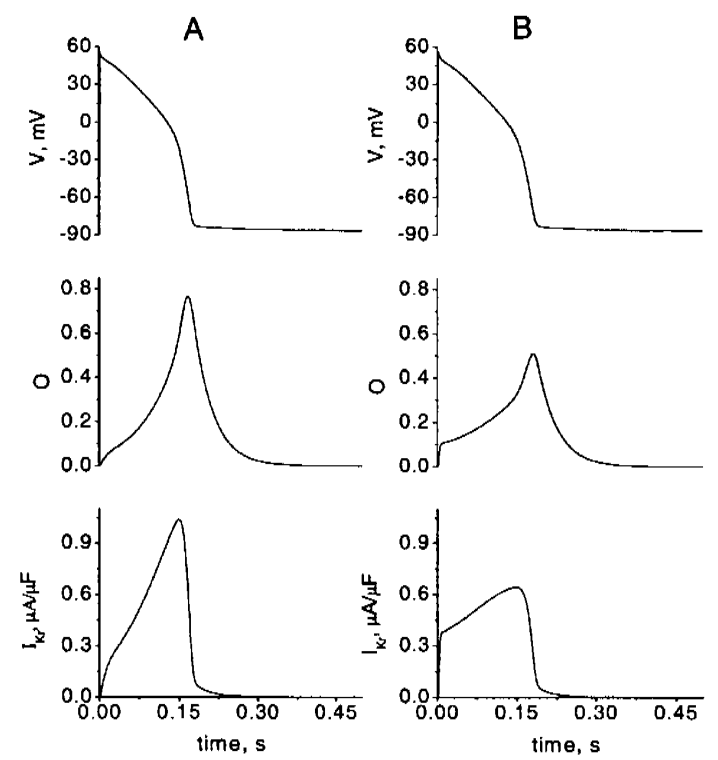

Figure 5: The comparison of the cardiac cell model with different representations of $\mathrm{K}_{\mathrm{r}}$ channel state probabilities. A: $\mathrm{H}-\mathrm{H}$ representation, B: Markovian representation.

At high pacing rates the difference in the behavior of channel's open probabilities during the AP is more pronounced (see Fig. 6 ). The corresponding difference in $\mathrm{I}_{\mathrm{Kr}}$ leads to $\sim 60 \%$ increase in APD for the Markovian model. 
A
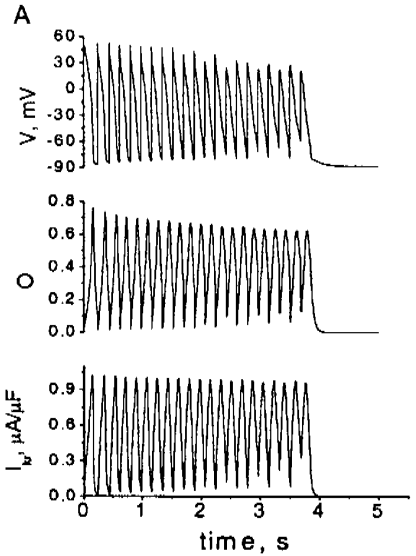

8
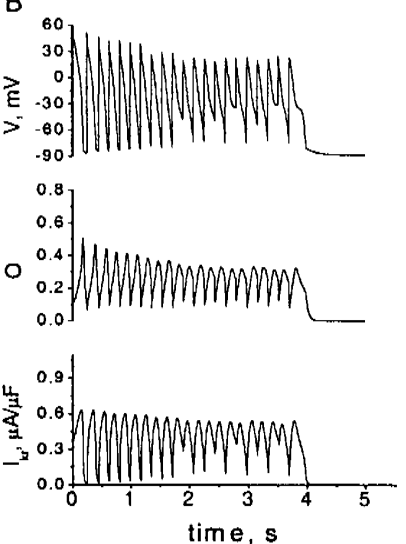

Figure 6: The cardiac cell model at high pacing rate $(\sim 180 \mathrm{~ms})$. A:

$\mathrm{K}_{\mathrm{r}}$ channels with $\mathrm{H}-\mathrm{H}$ formulation, B: Markovian formulation.

The significant decrease of the open probability of the channel at high pacing rate and corresponding decrease in $\mathrm{I}_{\mathrm{Kr}}$ allows us to suppose that a cell model with a Markovian representation will facilitate the appearance of EADs. Indeed, in Fig. 7 we demonstrate that at a high pacing rate EADs appear in the model with the Markovian representation for larger values of the coefficient $\mathrm{K}_{\mathrm{m}, \mathrm{ns}}$ (Ca) (smaller values of $\mathrm{I}_{\mathrm{ns}(\mathrm{Ca})}$ ) in comparison to $\mathrm{H}-\mathrm{H}$ representation.

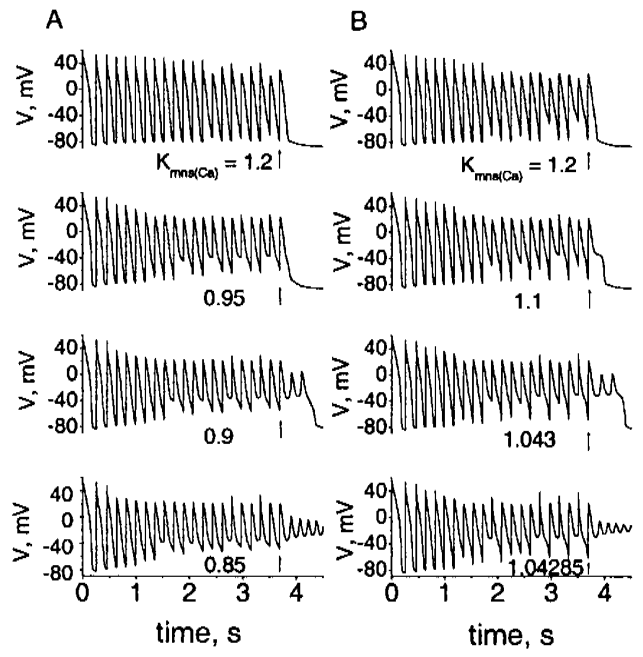

Figure 7: The $\mathrm{AP}$ patterns for equal $\mathrm{K}_{\mathrm{m}, \mathrm{ns}(\mathrm{Ca})}$ at a high pacing rate for different representations of the $\mathrm{K}_{\mathrm{r}}$ channel: A: $\mathrm{H}-\mathrm{H}$, B: Markovian. 
The arrows indicate the moment of last application of stimulus, which coincide with the moment of spontaneous SR Ca release. Indeed, the first double EADs appeared in the model with the Markovian representation for $\mathrm{K}_{\mathrm{mns}(\mathrm{Ca})}$ $=1.043 \mu \mathrm{mol} / \mathrm{l}$, while in the model with the $\mathrm{H}-\mathrm{H}$ they only appear if this coefficient is decreased to $0.9 \mu \mathrm{mol} / 1$.

\section{Discussion}

The more recent cardiac cell models with the $\mathrm{H}-\mathrm{H}$ formulation of the gating processes are based on measurements of macroscopic currents in single cells and the assumption of mutual independence of the channels' gate variables. The development of the single channel clamp-experiment technique has provided more accurate data that reveals the stochastic nature of the gating processes. This has led to the conclusion that channel state probabilities form an interconnected system, and that a more accurate way to describe channel gating is by means of Markov chains.

We have investigated here the effect of replacing the $\mathrm{H}-\mathrm{H}$ formulation of gating processes in sodium and fast potassium channels by a Markovian one (as developed by Clancy and Rudy for wild type channels) in the LR cardiac cell model with modified calcium dynamics. This particular model has a faster onset of calcium accumulation and spontaneous SR release. Our results show that at normal pacing rates there are no significant differences in the basic characteristics of the AP for either representation of gating processes. At high pacing rates (corresponding to tachycardia and fibrillation) the Markovian representations yield considerably greater decreases in open probabilities (hence in the corresponding macroscopic currents) for both channels. Since not all tissue cells are stimulated with "spiral wave periodicity", the greater $\left(\mathrm{I}_{\mathrm{Na}}\right)_{\max }=(\mathrm{dV} / \mathrm{dt})_{\max } \mathrm{de}-$ crease in the Markovian model will lead to an increased heterogeneity in wave propagation velocity and possibly to wave propagation instability. The greater decrease in $\mathrm{I}_{\mathrm{Kr}}$ affects the delicate balance of currents during the repolarization phase of the AP and could cause the appearance of EADs against the background of SR calcium overload - which is shown in ${ }^{18}$ to support nonstationary wave propagation.

The effect of introducing a Markovian representation for gating processes in the $\left(\mathrm{Ca}^{2+}\right)_{\mathrm{L}}$ channel will be investigated as soon as the required experimental data is available. Eventually we will explore how the (simultaneous) introduction of Markovian representations of gating processes for all three channels ( $\mathrm{Na}, \mathrm{K}$, $\mathrm{Ca}$ ) will affect isolated cell behavior as well as excitation wave propagation in $2 \mathrm{D}$ and $3 \mathrm{D}$ tissue.

Acknowledgements: This study was supported by supercomputing funding from National Energy Research Scientific Computing Center, Office of Energy Research of the US Department of Energy, under the contract No. DEAC0376SF00098. We also thank Jim Weiss and Eugene Chudin for useful discussions and comments. 
Simulations in Biomedicine $V$

\section{References}

[1] Hodgkin, A.L., Huxley, A.F., 1952. A Quantitative Description of Membrane Currents and its Application to conduction and Excitation in Nerve. J. Physiol., 117, 500-544

[2] Noble, D., 1962. A Modification of the Hodgkin-Huxley Equations Applicable to Purkinje Fiber Action and Pace-Maker Potentials. J. Physiol., 160, 317-352.

[3] Chudin, E., Garfinkel, E., Weiss, J., Karplus W. \& Kogan, B. 1998. Wave Propagation In Cardiac Tissue and effects of Intracellular Calcium Dynamics. Progress in Biophysics \& Molecular Biology, Vol 69, No 2/3, pp 2252362.

[4] Chudin, E., Goldhaber, J., Garfinkel, A., Weiss, J \&. Kogan, B. 1999. Intracellular Ca Dynamics and the stability of Ventricular Tachycardia. Biophys. J. 77, 2930-2941.

[5] Hille, B. Ionic Channels of Excitable Membrane. 1992. Sinauer Assoc.Inc. Second Edition.

[6] Armstrong, C. \& Bezanilla, F., 1997. Inactivation of the sodium current. I, II. J. Gen. Physiol, 70:549-590.

[7] Vandenberg, C. \& Bezanilla, F., 1991. Sodium channel gating model of the squid giant axon. Biophys. J., V 60, pp 1511-1533.

[8] Almers, W., 1978. Gating Currents and Charge Movements in Excitable Membrane. Rev. Physiol. Biochem. Pharmacol. 82: 96-190.

[9] Kuo, C. \& Bean, B., 1994. Na+ Channels Must Deactivate to Recover from Inactivation. Neuron, 12: 819-829.

[10] Sakmann, B. \& Neher, E., 1983. Single-Channel Recording. Plenum Press.

[11] Ervine, J., Jafri, J. \& Winslow, R. 1999. Cardiac Sodium channel Markov Model. Biophys. J., 76: 1868-1885.

[12] Jafri, M., Rice, J. \& R.Winslow. Cardiac Ca2+ dynamics. Biophys. J. 74:1149-1168.1998

[13] Clancy, C \& Rudy, Y., 1999. Linking a genetic defect to its cellular phenotype in cardiac arrhythmia. Nature, 400: 566-569.

[14] Clancy, C \& Rudy, Y., 2002. $\mathrm{Na}^{+}$channel mutation that causes both brigade and long - QT syndrome p henotypes. Circulation, 105. 1208-1213.

[15] Clancy, C \& Rudy, Y., 2001. Cellular consequences of HERG mutations in long QT syndrome: precursor of sudden cardiac death. Cardiovasc. Res. 50, 301-313.

[16] Luo, C. \& Rudy, Y., 1994. A dynamic model of the cardiac ventricular action potential Circ. Res. 74, 1071-1096.

[17] Zeng, J., Laurita, K.R., Rosenbaum, D.S. \& Rudy, Y., 1995. Two components of the delayed rectifier $\mathrm{K}+$ current in ventricular myocytes of the guinea pig type. Circ. Res. 77, 140-152.

[18] Kogan, B., Lamp, S., \& Weiss, J., 2002. Spiral Wave Regeneration by Early Afterdepolarizations in Simulated Cardiac Tissue. (Unpublished) 